\title{
The Preservation Evolution
}

\section{A Review of Preservation Literature, 1999-2001}

\section{JeanAnn Croft}

The literature representing 1999 to 2001 reveals that the preservation field is absorbed in an evolution. The literature demonstrates that trusted practices are changing to improve outcomes and further advance the preservation field. Simultaneously, in the wake of the digital revolution, preservation professionals dream about merging traditional and digital technologies in the hope that both long-term preservation and enhanced access will be achieved. This article attempts to relate the values of the discipline in order to inspire further research and persuade more work in formulating hypotheses to integrate preservation theory and practice. Finally, this overview of the literature will communicate the scope of the preservation problem, clarify misconceptions in the field, and document areas that warrant further investigation and refinement.

The literature representing 1999 to 2001 reveals that the preservation field is 1 continually absorbed in an evolution. This literature review examines the trends and customs of the preservation field as documented in the literature, and attempts to relate the values of the discipline in order to inspire further research and persuade more work in formulating hypotheses to integrate preservation theory and practice. Finally, this depiction of the literature will communicate the scope of the preservation problem, clarify misconceptions in the field, and document areas that warrant further investigation and refinement. Following up the preceding preservation literature reviews that have been published in this journal, this work provides a sampling of the preservation literature and will not include book reviews, annual reports, preservation project announcements, technical leaflets, and strictly specialized conservation literature. Exclusion of these works does not indicate any censorship, but is necessary to keep on target with the goals of this article and ensure a succinct and concise overview of the preservation literature.

JeanAnn Croft is Preservation Librarian, University of Pittsburgh, Pennsylvania.

Manuscript submitted August 29, 2002; revised manuscript accepted January 9, 2003.

\section{Preservation-Related Literature Reviews}

There have been several preservation literature reviews describing trends, convictions, and practices during their respective time periods. Coinciding with the observations that Drewes made in a previous review of preservation literature, current articles from 1999 to 2001 continue to integrate preservation management into the overall organizational structure of a library or archive (Drewes 1993). However, there is an attempt to take this assimilation a step further by 
incorporating secondary storage facilities and including digital technologies. Publishing case studies, presenting an overview of projects, and providing examples of how a procedure and practice are developed at a specific institution also remain constituents of the corpus of preservation literature as during the time of Drewes's review. Sophia Jordan conducted a review of preservation literature covering 1993 to 1998 and observed that the preservation field experienced a "refinement" and "maturation" (2000). The author reviewed a multitude of works and categorized them into subgroups including: Review of the Literature; Binding and Bindings; Physical Treatment, Reformatting (Microfilming and Photoduplication); Audio-Video, Film, and Photographic Materials; The Digital Arena; Environment Control; Disaster Planning; and Management. Jordan's examination concluded that "preservation librarians have reflected upon themselves and have developed an historical perspective of themselves" (2000, 10).

Consistent with both Drewes's and Jordan's literature reviews, preservation literature continues to thrive at this time (Drewes 1993; Jordan 2000). The fact that literature reviews are being conducted on digital documents and music collections, focusing specifically on the preservation issues relating to these mediums, is evidence of a blossoming of literature. These reviews testify to both Drewes's observation of a "widening circle" $(1993,315)$ and Jordan's noting "refinements in established preservation concerns" $(2000,5)$. The authors represent specialized fields outside of preservation and recognize the mortality of digital documents and music collections. Smith claims that the literature "signifies an urgent appeal . . . to preserve the priceless musical heritage" $(2000,135)$, while Parkes observes that the literature has "identified the major preservation issues as being the physical deterioration of digital media and the rapid rate of technological obsolescence" (1999, 374).

Jordan recognizes that "If the literature of the early 1990 's reveals an explosion of information . . . then the preservation literature covering 1993-1998 shows refinements in established preservation concerns and a maturation and leadership in the new frontier" $(2000,5)$. Consequently, the literature representing 1999 to 2001 reveals that the preservation field is continually absorbed in an evolution and is on the verge of a revolution. The literature demonstrates that trusted practices are continuously evolving to improve outcomes and further advance the preservation field. Simultaneously, in the wake of the digital revolution, preservation professionals dream of merging traditional and digital technologies in the hope that both long-term preservation and enhanced access will be achieved. This technological revolution will continue to influence preservation services in the future and lead to a collaboration of resources across disciplines.

\section{Clarifying Preservation Misconceptions}

The journey to achieve both preservation and access has not been an easy one, and chosen paths have been challenged. Library and archives professionals recognize microfilm as the most dependable preservation medium; however, the public does not embrace this technology as a satisfying tool for access. Nicholson Baker's publication Double Fold: Libraries and the Assault on Paper (2001) has stirred up controversy in the library and archival world, specifically in the area of preservation and destruction of original text for preservation purposes. Reviews and articles in publications such as the New Yorker, The New York Times Book Review, and Washington Post Book World have contributed to the work's notoriety. Baker chastises libraries for their microfilming practices of not retaining original materials such as newspaper in their permanent collections, and contends that the "brittle book crisis" is not as critical as it has been portrayed in the library and archives world. Although Baker's interest in preservation is admirable, he is critical of many practices that are now obsolete and does not tell a complete story. Libraries and archives often seek funding and support from the public and are quite concerned about the fallout of such negative and uninformed publicity. Consequently, librarians and archivists are attempting to mitigate the negative press received with the publication of the book by addressing issues that were raised and offering an explanation of what practices are implemented today and what can realistically be accomplished within the means of an institution. Libraries and archives realize that they must do a better job in pleading their case to the public and increasing awareness of current preservation initiatives. Baker's publication provides a rallying point for preservationists to reassert their value and effectiveness. Double Fold inspires the necessity for expanded education in preservation, as well as constant evaluation of these practices set forth by the preservation community to ensure that collections are accessible for the future.

Michèle Valerie Cloonan challenges preservation professionals to look critically at their role and the profession as the trend toward the decline in preservation programming in Association of Research Libraries (ARL) and schools teaching library and information sciences indicates a weakening of the field (2001). Sophia Jordan believes that a review of literature demonstrates "that the work in the field suggests a 'coming of age' for preservation. Preservation has been a part of libraries both as an administrative unit and as a unified practice long enough now to have developed a history, methodology, a series of sub-specialties, and, yes, even philosophical schools" (2000, 5). However, Cloonan (2001, 239) disputes this viewpoint because social issues concerning the survival of cultural 
heritage materials are not discussed in the literature included in that review. The author explains that preservation is more than prescribed treatments and solutions and requires a better understanding of the cultural context that surrounds an object (Cloonan 2001).

\section{Importance of the Artifact}

As if in response to the concerns presented by Baker and Cloonan, the recent literature reveals a renewed and refocused commitment on the part of the pubic to the original artifact. Cloonan points out that public interest is a driving force in establishing preservation as a priority when or while the public looks to cultural institutions to preserve their heritage (2001). Tools such as eBay, Bibliofind, Abebooks, auction sites, and various other Web sites facilitate researching the availability and value of an item and increase preservation awareness in the public domain. Reminded of the preservation challenges posed by digital technology and recognizing the public demand for original items, professionals are cognizant of the virtues of the artifact, thus placing a new emphasis on preserving these items. With an awareness that it isn't feasible to preserve everything, the literature shows how librarians and archivists are mindful that decisions about the final disposition of an item cannot be made in a vacuum. Professionals representing diverse branches of learning must offer perspective and advice to assist in making intelligent decisions about which items should be saved and preserved for posterity. Furthermore, Cloonan believes that these stakeholders will address the social issues essential to the preservation of cultural heritage materials (2001). The literature provides a representation of the work that assorted professionals are engaged in and the direction that the profession is taking in regard to cultural artifacts.

Various professionals across disciplines have presented a united front in justifying the preservation of artifacts. In 1995, the Modern Language Association (MLA) authored the "Statement on the Significance of Primary Records" to facilitate discussions concerning the responsibility of libraries in an increasingly electronic environment. ARL took up this cause, which resulted in the creation of the Preservation of the Artifact Task Force. The ongoing directive of this group is to provide awareness and insight regarding the preservation implications of the original format and to create strategies to address these issues (Enniss 1999). Another group researching and investigating the role of the artifact is the Council on Library and Information Resources (CLIR). CLIR established a task force of scholars, academic officers, librarians, and archivists, which yielded several recommendations including campaigning for the development of repositories for artifacts, promoting good stewardship, and investigating best preservation practices for the artifact (Nichols and Smith 2001). CLIR also commissioned a study to concentrate on research concerning preservation and conservation of analog and archival materials. Paper, film and photographic materials, and magnetic tapes illustrate the technology of the nineteenth and twentieth centuries and serve as the focal point of research. The report summarizes significant developments in preservation and conservation research conducted in the last five years and identifies various trends in the profession, recognizing areas that require additional work and research, such as active conservation of individual artifacts, standards for mass deacidification and accelerated-aging tests, determination of the life expectance of magnetic tape, and effects of solvents and solvent residues (Porck and Teygeler 2000).

Organizations such as the National Preservation Office (NPO) in the United Kingdom and the National Centre for Conservation and Restoration (NCCR) in Chile are engaged in devising national preservation plans to protect their cultural heritages. The NPO developed a forum to coordinate a national preservation effort to include information and referral service, preservation education and training, and the coordination of research and evaluation. Various committees of professionals and commercial sponsors provide for and support this effort (Marshall 1999). The NCCR also sought counsel from advisors, preservationists, and conservators throughout various institutions in Chile as well as representatives from CLIR. Its directive was to set the groundwork for the creation of a library network and offer seminars in preservation training (Palma 2001). Furthering this pursuit is the Landerestaurierungsprogramm (State Restoration Program) in Germany, which increases public awareness through consulting and training efforts about the importance of preserving cultural heritage in danger of extinction. This program consolidates resources and experts in conservation to serve the regional libraries and archives via microfilming and conservation services (Haberditzl 2001). These organizations illustrate the power of collaboration: each draws resources and expertise from among different disciplines and professions to formulate committees, working groups, and organizations, realizing that each faction delivers a different strength and point of view to these ventures.

Mark Herring provides a slightly different perspective on preserving the artifact. Herring's concern for the cultural artifact brings forth the bold realization that if an institution cannot properly preserve an item, then it shouldn't accept this responsibility in the first place (Herring 2000). Arguing the merits of deaccessioning, Herring demonstrates that depositing the artifact in an institution with the appropriate resources will bring about more space, financial revenue, and improved preservation for the items that require specialized care. Supporting Herring's arguments, Gehret advocates that collection developers incorporate 
preservation into their overall collecting and purchasing scheme and discard items when their use and importance to the mission of the institution diminish (Gehret 1999). Conversely, Baker believes that everything should be saved and recommends that institutions make available a discard list so that the public can hold them accountable "to act responsibly on behalf of their collections." Believing that libraries and archives have failed in their preservation responsibilities, Baker constructed a newspaper warehouse to safeguard materials from disposal (2001, 270). CLIR's task force acknowledges that it is not possible to save everything and that formulating a preservation strategy is necessary to contend with the notion that it is difficult to predict an item's value and worth into the future, and that materials must be carefully selected for preservation and access (Nichols and Smith 2001). Librarians and archivists enable the lines of communication between the present and the past through collection and preservation by avoiding an attempt to save the same kinds of materials, but rather by identifying which materials should survive from each period.

\section{Remote Storage}

In addition to preserving cultural artifacts, a documented and well-known problem that libraries and archives encounter every day is the lack of adequate space to accommodate their growing collections. Jan Merrill-Oldham and Jutta Reed-Scott's ARL SPEC Kit \#242, Library Storage Facilities, Management, and Services, surveyed fifty-eight ARL member libraries to compile information about building design, environmental conditions, fiscal and personnel management, materials handling, and document delivery (Merrill-Oldham and Reed-Scott 1999). This survey reveals the severity of the space problem and confirms that the majority of ARL libraries use secondary storage facilities to house collections. These remote storage facilities have also presented other opportunities, such as providing climatecontrolled storage and housing collections at a cost savings. For example, the State Library at Queensland designed and constructed two cold storage vaults located in close proximity to the library in the parking lot to house a portion of the photographic collection. The design of these vaults includes strict environmental conditions, security, and appropriate shelving and storage furniture to prevent further deterioration of film-based collections (Egunnike 2001).

Remote library storage is further discussed in the literature and touches upon the logistics of incorporating this facility into the overall institution while maintaining easy access to the collection. Two examples of such facilities are the Five-College Library Depository in Massachusetts and the Preservation and Access Service Center for Colorado Academic Libraries (PASCAL). The Five-College Library
Depository consists of five colleges (Amherst College, Hampshire College, Mount Holyoke College, Smith College, and the University of Massachusetts at Amherst) that have agreed to create a shared library in a centralized location. Assuming joint responsibility of a combined collection created through the deaccession of duplicates, these five institutions reap the benefits of cost savings, better environmental conditions for materials, and increased security (Bridegam 2001).

Following the Harvard model, institutions in Colorado also participate in a joint effort to acquire and maintain a high-density remote storage facility (Fry 2000). Similar to the Five-College Library Depository, PASCAL experiences the challenges in shared ownership and managing the logistics of operating an off-site storage facility, while maintaining quality service for their patrons. Interestingly, remote storage is not only seen as an answer to the space predicament, but is also viewed in the literature as an option to preserve cultural artifacts and an opportunity to create last copy depositories for both print and electronic publications (Kisling, Haas, and Cenzer 2000).

Nicholson Baker recommends that the Library of Congress (or another entity designated by Congress) create an off-site depository to accommodate everything that is sent to it by publishers (Baker 2001). It is not possible for one entity alone to shoulder so great a responsibility, because the resources and funding needed to operate such a facility are colossal and almost impossible to secure. CLIR's Task Force on the Artifact in Library Collections advocates the creation of regional repositories to jointly preserve artifactual collections, which is a more realistic solution. In addition, this task force proposes that an American imprint repository be fashioned at the national level to ensure that at least one copy of copyrighted material will endure (Nichols and Smith 2001). The evidence of research and development, collaborative efforts to investigate and preserve cultural artifacts, and planning for the storage of these objects presented in the literature demonstrates the value and dedication of the profession to ensure that these materials will endure.

\section{Mass Deacidification}

The preservation field is making strides in developing standards and implementing codified best practices. The emergence of standards represents ongoing discussions, debates, and communications among practitioners in the library and archival fields to address universal concerns. Traditional preservation topics such as physical treatment and binding continue to flourish in the literature as well as the standards that are developed to support these endeavors. Preservation managers explore mass deacidification projects and are 
attempting to incorporate mass deacidification into the overall preservation program. Worthy of mentioning, the literature shows that deacidification is usually conducted in tandem with another preservation option such as commercial binding or reformatting. The literature discusses issues such as paper degradation, evaluation of the deacidification processes, selection, workflow, and quality control that contribute to designing best practices.

Penn State University Libraries combines commercial rebinding of monographs in the circulating collection with mass deacidification (Kellerman 1999), while Johns Hopkins University selects items that are considered to be at risk and deemed as possessing long-term research value for mass deacidification. These monographs are sent directly to the plant for mass deacidification, while the commercial binder routes acidic journals to the deacidification facility (Drewes, Smets, and Riley 2000). The Library of Congress conducted extensive testing on mass deacidification, endorsed the work of Preservation Technologies, L.P. (PTLP) in Cranberry, Pennsylvania, and continues to work with PTLP to improve the Bookkeeper mass deacidification system. In addition to researching the Bookkeeper system, LC devised selection criteria and procedures for preparing selected materials for shipment (Harris 2000).

Robert Strauss discusses the role of deacidification within a preservation program by indicating that mass deacidification should not necessarily replace but should complement other preservation activities (2000). Combining various techniques such as commercial rebinding and/or reformatting with deacidification highlights the importance of preservation and access to materials and at the same time utilizes resources efficiently. Deacidification presents a less expensive alternative to creating a preservation facsimile and microfilm and has the potential for cooperative resource sharing (Drewes, Smets, and Riley 2000). These articles demonstrate that research on deacidification transformed from evaluating and perfecting deacidification technologies to establishing policies and procedures to implement a mass deacidification program and expand it to include reformatting, binding, and planning for collaborative efforts.

\section{Physical Treatment and Commercial Binding}

The preservation field is persistent in introducing innovative techniques and procedures in the literature. Hingley conducted research to determine if conservators were utilizing suction tables to treat parchment and further discussed the specifications used for purchasing a suction table, treatment processes, and the conclusions drawn from this research (Hingley 2001). In addition, paper splitting is developing as a preservation option for embrittled paper. Although paper splitting dates back to the nineteenth century, new technology and equipment demand a reexamination and consideration of this process (Smith 2000). Kerstin Forstmeyer researches the topic of minimal conservation intervention to reaffirm "the most extensive retention of the original substance" (72). This case study explored the restoration practices and techniques conducted on a manuscript containing the Estate Register Accounts Book (Forstmeyer 2001).

Moving away from single-item treatment is the management aspect of rare book conservation. Pauline Kamel discusses various options available in treating rare books, how to select a conservator, and the importance of establishing priorities (Kamel 1999). In addition, the development of the ANSI/NISO Standard, Guidelines for Information about Preservation Products, encourages vendors to use accurate and consistent language and suggested data elements when describing all products (National Information Standards Organization 2000a). As a result of this standard, librarians, conservators, and archivists can better evaluate and review preservation products and communicate to the vendor the most appropriate product to suit their needs.

Complementing the articles on or about physical treatment are those articles that focus on binding. Standards benefit the field because they are reviewed and maintained regularly in an ever-changing environment. The ANSI/ NISO/LBI Z39.78-2000 standard, Library Binding, was recently revised and put into effect in 2000 and will again be reviewed in 2005. The most recent version of the standard incorporates allowances for flat-backed text blocks, recognizing that this process may be less expensive than rounding and backing (National Information Standards Organization $2000 \mathrm{~b}$ ). This standard provides guidelines for a very effective preservation treatment by providing a glossary of terms and specifications for the technical processing and materials used in binding. These specifications allow binders and institutions to negotiate a mutually beneficial and understood binding contract to ensure that all parties involved are familiar with the binding process and vocabulary. There is a series of articles that examine different types of bindings or attributes of these bindings and another category that investigates the managerial aspect of a binding program and the binding program itself. Werner Rebsamen authored several articles on binding aspects that are featured in New Library Scene. The comparison of edition bindings to library bindings leads to the conclusion that the quality of edition bindings has decreased steadily and does not measure up to the quality of library binding (Rebsamen 2001a).

The literature also discusses other styles of binding such as pamphlet binding. Shannon Zachary's article provides guidelines in selecting items to bind, the type of supplies and equipment that are necessary in pamphlet binding, and workflow (2000). New challenges that will 
make an impact upon library binding programs and practices appear in preservation literature. For instance, the question of binding and maintaining paper journals while investing in electronic versions of these periodicals is continually being evaluated (Anderson 1999). The fate of library binderies is brought to question as binderies are disappearing from the scene. George Cooke argues that library binders serve as resources to extend the life of collections and offer services for circulating and rare books and preservation photocopy reformatting (1999). Reiterating that hand bookbinding is not a dying art, Werner Rebsamen discusses the history of the bookbinding craft and talks about the successful program "Bookbinding 2000," an event that honored Bernard C. Middleton (Rebsamen 2001b). These articles on physical treatment and bindings solidify the dedication to conservation and preservation by examining challenges that face the field, investigating best practices, and revisiting traditional techniques that can be improved upon to ensure proper preservation and the best use of resources

\section{Contingency Planning, Environmental Control, and Integrated Pest Management}

Literature about contingency planning, environmental control, and integrated pest management further demonstrates support for traditional preservation programming. This category of literature appeals to a varied audience with different specializations since the periodicals in which they are featured represent management, archives, and public, academic, and research institutions. These articles are proactive and reactive in nature, not only illustrating preservation awareness, but also proving that experience, trial and error, and mistakes serve as a strong reminder about the importance of careful planning. Some of the literature is didactic and provides instructions for disaster prevention and planning that can be instituted at a home institution. Kim Kane discusses how the San Diego County Public Law Library wrote a disaster plan shortly after attending a workshop on disaster preparedness and gives pointers and tips on how to go about creating a disaster plan (2001). Page offers a very in-depth look at disaster planning by reminding readers that disaster prevention and preparedness is a role for all library staff, providing resources to assist in initiating or revising disaster planning, and discusses lessons that had been learned through disasters (1999).

However, some authors share what they have learned through their disaster experiences in the literature in hopes that other institutions can build upon their knowledge for an expedient recovery. Mary Reinerston-Sand describes how archival training enabled her to salvage irreplaceable personal memorabilia during a flood in 1997. She provides details of the salvage operation and discusses what was learned from this experience, as well as emphasizing the importance of creating back-up photocopies of important papers and storing them off-site (Reinertson-Sand 1999). The Colorado State University Libraries survived a water disaster in 1997 when heavy storms smashed a hole in the basement and saturated the collections. The recovery effort continues today, and even though the university maintained a disaster plan, they admittedly were not prepared for an emergency situation of this caliber (Lunde 1999). Following the disaster, offers to help through gifts in kind, monetary contributions, and services overcame the university. The university is replacing the materials and rebuilding the collections with gifts in kind instead of attempting to restore damaged materials (Johnson 1999). Other examples include the National Library of Australia barely escaping a fire in March 1985, which inflicted smoke damage to the building and collections and water damage to the collections. Throughout the salvage and recovery efforts, the library realized that it was unprepared to deal with such an emergency, and it established a disaster-planning committee to create a plan and a register of collection priorities of nationally significant materials and to continue to review and update the plan based on what was learned during subsequent disasters (Preiss 1999).

War and terrorism devastate libraries and archives. Disaster planning quickly changed in the United States when the terrorist attacks on September 11, 2001, destroyed special libraries operating in the World Trade Center (WTC) in New York City. DiMattia emphasizes the need for a contingency plan that incorporates flexibility, teamwork, duplication of data, and networking (2001). Such a catastrophic event reinforces the necessity of contingency planning to respond and salvage collections; however, the terrorist attacks rendered an inconceivable emergency a reality. As a result, institutions are revising their plans to address terrorism. Shortly after September 11, several high profile institutions such as Los Angeles's central library, Las Vegas/Clark County Library, and Boston Public Library heightened security measures and now conduct bag inspections, monitor entrances and exits, and increased the presence of security officers. These institutions are working collaboratively with agencies located within close proximity to coordinate evacuation plans (Kenney 2001).

Other institutions are still recovering from the spoils of war and terrorist acts. A conference in Sarajevo presented a model encouraging improved relations among Bosnians, Croats, and Serbs, and offered educational programming such as workshops in conservation and restoration and courses in disaster management (Mader 2001). The International Committee of the Blue Shield continues to develop initiatives to protect endangered cultural heritage from armed conflict by prioritizing records and creating 
finding aids, conducting risk assessments, establishing evacuation procedures, and examining the characteristics of the building (MacKenzie 2000).

A key component in disaster response is working to stabilize the environmental conditions in an institution. Providing a suitable environment for collections proves extremely difficult, but is the most effective method in preventing mold outbreaks and pest infestations, and it impedes the chemical deterioration processes in books, paper, and film-based media. The Heritage Collections Council, Department of Communications, and Information Technology and the Arts are investigating the use of passive environmental conditions for small cultural institutions across Australia. Pearson and King recognize that not all institutions have the means or resources to effectively control environmental conditions, and provide creative ways of dealing with these challenges (2000). Environmental conditions permeate throughout all aspects of collecting and preserving, and making collections available for research and exhibitions is no exception. The ANSI/NISO Z39.79-2001 standard, Environmental Conditions for Exhibiting Library and Archival Materials, describes how to create the optimal environment for exhibits. The standard takes into consideration the type of materials exhibited, localization of climate and environment, technologies determining or impacting the environment, compromises for human comfort levels, limitations of exhibit space, and financial considerations (National Information Standards Organization 2001a).

Articles articulating the problem of mold and abatement techniques provide ammunition for institutions that will face this serious problem in the future. Mold infestation has plagued North Carolina, Arkansas, and Queensland, Australia, over the course of the past few years. Each author discussed the conditions that are favorable for mold; Eastern Carolina University and Arkansas achieved this environment when their heating, ventilation, and air conditioning (HVAC) systems went awry, while Australia experienced leaking around the library balcony windows. East Carolina University's Joyner Library hired a temporary team to clean each book with HEPA vacuums and dry sponges to remove the mold and cleaned the shelving units with a Lysol/water solution (Smith 1999). Arkansas State University followed a similar plan of attack in mold remediation, the only difference being that the university's housekeeping crew worked alongside library staff and teaching faculty executing the cleanup effort (Moore 1999). The Australian Institute of Marine Science in Queensland retained the services of a Brisbane-based company, Moisture Control Services, to rid the collection of mold with a chemical spray solution after unsuccessful attempts to eradicate the mold internally (Temby 2001).

Each author stresses the importance of monitoring environmental conditions to prevent any further outbreak of mold. In addition, pest infestations occur when environmental control is disrupted and also serve as an indicator that there is a problem with the climactic conditions. The Main Library of the University of the South Pacific in Suva, Fiji, and the Marciana National Library in Italy both implemented preventive pest control programs as a result of infestations. The University of the South Pacific required mass fumigation of larvae in the general collection. The library considered both chemical and nonchemical techniques, but the severity of the infestation dictated the use of methyl bromide gas to sterilize the materials (Fong 2001). The Marciana National Library experienced an infestation of woodworms and employed anoxic fumigation to kill the pests by removing oxygen from their environment (Plebani 1999). R. E. Child also emphasizes integrated pest management as a preventive tool to eliminate conditions that are favorable to pests, including good building design, housekeeping policies, environmental control, and careful monitoring (Child 1999).

\section{Unique Formats}

Institutions endeavor to maintain core preservation programs while expanding to include unique formats and services. Articles point out that preservation decisions are often made by either format or content. Furthermore, the literature narrates the emergence of new formats that require specialized preservation attention, and raises awareness of the challenges they pose. As in the case of the articles on physical treatment, these articles serve to broaden the knowledge base and promote information sharing. For example, the collection of visual ephemera is introduced and defined, and the conservation issues are discussed (Slate 2001), while access to three-dimensional collections is limited because of the fragile nature of these materials. The Web offers possibilities of expanding access to these collections, while protecting the original item from harm (Jarrell 1999). Architectural plans and film preservation continue to deteriorate and present challenges to collection institutions. The University of Dundee, Scotland, conducted a survey to address the conservation of architectural plans (Tait and Sterlini 1999), and discussed strategies for film preservation (Poole 1999). Impermanence and degradation of original formats often yield content- and information-driven projects. For example, McGlamery and Read discuss the latest computer technologies, such as digitization and print-on-demand equipment, which are utilized to preserve the informational content of maps (McGlamery 2000; Read 1999). The articles evaluate the nature of the information contained in maps and their use patterns in designing the most appropriate solutions. Other project-oriented articles dealing 
with unusual formats include preserving oral history from audiocassette to digital archive (Hall 2000) and preserving the local history of an African American community on CD-ROM (Johnston 1999). Sophia Jordan observed that, "Preservation librarians have not been particularly adept at dealing with the preservation issues associated with nonbook formats that populate our libraries" (2000, 7). Unfortunately, this trend does not appear to have changed, as the amount of literature pertaining to these formats is sparse, and more research is necessary to grapple with these issues.

\section{Preservation Reformatting}

Literature on or about preservation reformatting manifests itself in different ways, such as evaluating current reformatting procedures, surveys and assessments of materials already reformatted, overview of reformatting programs at various institutions, successes and challenges of specific projects, and migrating from an analog to a digital format for preservation purposes. As in the case of environmental control and contingency planning, experience is a valuable teacher. Most attention is given to microfilming as a reformatting option. Berger and Cybulski discuss project management, trends in reformatting, financial issues, and the quality assurance of reformatting projects (Cybulski 1999). Lane and Gudz provide an overview of reformatting showing an evolution from microfilming and photocopying to also include scanning and digitizing (Lane and Gudz 2000). Assessments of Yale's negative microfilm collection (Walls 2000) and the University of Kentucky's newspaper negatives (Teper 2001) provided examples of different assessment and survey techniques, and resulted in discoveries that include the need for improved bibliographic control, improved environmental conditions, continuation of polysulfide treatment for polyester-based film, a system of assigning reel numbers, different storage and arrangement techniques of film, and delegation of the film collection to a subject specialist or other librarian. These articles provide models for explaining different methods of conducting a survey and assessment of microform collections, the type of data that can be excluded from such studies, and conclusions and recommendations that can be surmised and shared within the profession. Reports documented the procedures, challenges, and successes of several microfilming projects that were undertaken (Johnson and Walter 2000; Bernthal and Walter 2000; Perushek and Smith 1999; Stoker 1999). Microfilm is deemed to be the most enduring preservation medium, lasting five hundred years with proper storage and handling. The ANSI/NISO Z39.62-2000 Standard, Eye-Legible Information on Microfilm Leaders and Trailers and on Containers of Processed Microfilm on Open Reels (National
Information Standards Organization 2001b) provides useful instruction on the essential data necessary for identification, filing, and retrieval of information on microfilm. This standard helps to provide a foundation for preservation microfilming to enhance collaborative microfilming projects, define terminology and create a common language for institutions and vendors to share, facilitate resource sharing, and instill confidence that research materials are being preserved in a responsible manner for the long term. Reformatting technologies, such as the creation of preservation facsimiles and microforms, address the preservation aspects of deteriorating materials and pave the way to incorporating digitization as a preservation tool.

\section{Educational Endeavors}

As technologies revolutionize preservation programs and services, the need for collaboration among professionals will be more important than ever to ensure that limited resources can sustain new formats while maintaining traditional preservation programming. Cooperation between the interested parties within a given institution will guarantee that preservation is integrated throughout the archive and library systems. Because ignorance is a huge culprit in damaging library and archival collections, educational programming will foster learning and a sense of involvement by staff across the entire system. Some articles provide guidelines on how to conduct an educational program and others explain how preservation is a role and responsibility that every institution and employee should participate in (Henderson 2000; Schobernd 1999). Methods for assessment and evaluation are required to ensure that preservation education and programs are addressing the preservation needs of an institution (Eden et al. 1999; Wiseman and Darby 2001). The literature also shows that preservation schemes are derived from specific areas such as collection development. Preservation factors into decisions made by subject specialists regarding selection, acquisition, and budgeting (Gehret 1999). In addition, deterioration by subject category serves as an impetus in designing collection surveys and strategies (Wishard and Musser 1999; Schaffner and Baird 1999).

\section{Digital Technology and Preservation}

The literature also demonstrates that preservation professionals are attempting to bridge the gap between a scholar's desire for immediate and long-term access and the creation of current strategies designed to address these preservation challenges. The number of articles written about digital technology is staggering, and this review of literature pres- 
ents only a sampling of the information available. Articles that focus on the digital world seem to follow a number of patterns including an overview of the benefits and drawbacks of digitization for preservation, case studies and reports on digital projects, and technical issues concerning the infrastructure of digital documents. It is interesting to note that these articles are featured in a broad corpus of library and archival sources. The potential and merits of digital technology are weighed against the challenges and limiting factors inherent in the technology, and the misconception that digitization is preservation is clarified.

These issues are evaluated and discussed in a variety of articles including: A. Smith (1999a and 1999b), Tennant (1999), and Larsen (1999). Digitization alone is not considered a preservation option because life expectancy, technological obsolescence, and longevity come into question (Gertz 2000). Furthermore, it is not possible to verify the authenticity of a digitized item (A. Smith 1999b). Both Gertz and Smith agree that digitization enhances access and research and exceeds traditional preservation reformatting tools. Digitization is often coupled with other preservation techniques. For example, Helsinki University combines the digitization of the newspaper collection with preservation microfilm (Bremer-Laamanen 2001).

As the library and archival communities continue to digitize materials for increased access on the Web, there is the hope that someday digitization will, in turn, constitute preservation. Projects employing digital technology are discussed in a multitude of articles. There is a shift in the responsibility of archiving as publishers and agents play a more prominent role in archiving electronic texts. Libraries and archives will not be able to justify the dual expense of retaining both paper and electronic journals, and discover that they are relying more on publishers to fulfill this role (Flecker 2001). There are several articles that pertain to electronic journal archiving. William Y. Arms explores the level of preservation required to sustain the Association for Computing Machinery (ACM) Digital Library, the Internet RFC Series, and D-Lib Magazine, and considers whether the publisher should serve as an archivist and take responsibility to refresh and migrate the information (Arms 2000). The Canadian Architect and Builder project aspires to provide online access to the full text and contribute this work to the Journal Storage (JSTOR) project. The article focuses on the preparation and scanning procedures utilized in this project and the problems that were encountered ( $\mathrm{M}$. Berger 1999). In addition, the National Library of Australia, in cooperation with the State Libraries of Australia, is also attempting to create an online archive of Australian publications in the PANDORA Project (Law 2001). The Royal Library of Sweden is following suit in creating a digital archive, which extends its collection policy to include electronic publications in Sweden. The library is devising strategies to take snapshots of the Web several times a year (Arvidson 2001). Digital archiving also presents other unprecedented challenges to information professionals. For instance, institutions that serve as a legal depository of records may have to incorporate digital publications into their collection and retention policies. However, this policy does not guarantee the long-term preservation of these digital archives (Muir 2001). Bearing responsibility for sustaining a digital archive is an expensive venture plagued with refreshing and migrating issues. Although publishers are currently taking a part in this role, cooperative planning and resource sharing are necessary to develop standards and successfully retain these records in the future.

Although solutions to the long-term preservation of electronic journals and other digital formats are in the offing, formats that have the greatest chance of long-term survival are a continued theme in the literature. Jeff Rothenberg dissected the issues concerning long-term preservation of digital technology and recommends the emulation strategy as the most viable solution compared to reliance on hard copies, standards, computer museums, and migration (1999). Paul Wheatley's view on migration and emulation differs from Rothenberg in his belief that both strategies will be incorporated into preserving digital materials for the long term. Emulation will serve a greater purpose to preserve complex objects incorporating software, while migration will be reserved for more simple data objects (Wheatley 2001). Rothenberg views migration as too unpredictable and complicated upon discovering errors and loss or corruption of data (1999).

Institutions that place a great emphasis on preservation are engaging in digitization projects. Given their skill and experience in evaluating and implementing reformatting projects, they bring extensive knowledge from which to foster the development of new standards for the digital age. In harmony with preservation efforts, digitization projects have sharpened the focus on some of the preservation issues facing libraries and archives today. Several case studies and projects contribute to the knowledge base of preservation and digitization (Lossau and Liebetruth 2000; Wheatley 2001; M. Berger 1999).

\section{Conclusion}

The literature written on preservation shows that the field has constantly been advancing and evolving best practices to include unique formats while maintaining traditional preservation. On the threshold of a revolution, Abby Smith (1999c, 1) comments that "wide dissemination of digital surrogates has created fresh demand for use of primary sources in their original media." Much of the preservation literature testifies to the importance of the original artifact and demands that 
collaborative efforts will yield fruitful strategies. This development promises exciting possibilities in obtaining longterm preservation and enhanced access to collections.

\section{References}

Anderson, Iris W. 1999. To bind or not to bind. Information Outlook 3, no. 11: 24-28.

Arms, William Y. 2000. Preservation of scientific serials: Three current samples. Microform and Imaging Review 29, no. 2: 50-56.

Arvidson, Allan. 2001. The royal Swedish Web archive: A "complete" collection of Web pages. International Preservation News 26: 10-12.

Baker, Nicholson. 2001. Double fold: Libraries and the assault on paper. New York: Random House.

Berger, Barbara. 1999. Lessons learned in the trenches: Preservation microfilming after thirteen years. Microform and Imaging Review 28, no. 3: 91-93.

Berger, Marilyn. 1999. Digitization for preservation and access: A case study. Library Hi Tech 17, no. 2: 146-51.

Bernthal, Rebecca, and Katherine Walter. 2000. Preserving our agricultural heritage. Nebraska Library Association Quarterly 31, no. 4: 10-15.

Bremer-Laamanen, Majlis. 2001. A Nordic digital newspaper library. International Preservation News 26: 18-20.

Bridegam, Willis. 2001. A collaborative approach to collection storage: The Five-College Library Depository. Washington, D.C.: Council on Library and Information Resources.

Child, R.E. 1999. Insect pests in archives: Detection, monitoring and control. Journal of the Society of Archivists 20, no. 2: $141-48$.

Cloonan, Michèle V. 2001. W(h)ither Preservation? Library Quarterly 71, no. 2: 231-42.

Cooke, George W. 1999. Will library binders disappear? New Library Scene 18, no. 1: 6-7.

Cybulski, Walter. 1999. You say you want a resolution? Technical inspection and the evaluation of quality in preservation microfilming. Microform and Imaging Review 28, no. 2: 56-67.

DiMattia, Susan S. 2001. Planning for continuity. Library Journal 126, no. 19: 32-34.

Drewes, Jeanne. 1993. A widening circle: Preservation literature review, 1992. Library Resources and Technical Services 37: 315-22.

Drewes, Jeanne, Kristine Smets, and Cheryl Riley. 2000. Deacidification of journals: Saving the past and present for the future-you mean publishers aren't using alkaline paper? Serials Librarian 38, no. 3/4: 269-76.

Eden, Paul, et al. 1999. Developing a method for assessing preservation needs in libraries. Library Management 20, no. 1/2: $27-34$.

Egunnike, Lydia. 2001. A cool change cold storage at the State Library of Queensland. International Preservation News 24: 26-28.
Enniss, Stephen. 1999. Collaborative values and survival of the print record. College and Research Libraries News 60, no. 6: 459-60, 464.

Flecker, Dale. 2001. Preserving scholarly e-journals. D-LibMagazine 7, no. 9: 1-9. Accessed July 7, 2002, www.dlib. $\mathrm{org} / \mathrm{dlib} / \mathrm{september01/flecker/09flecker.html.}$

Fong, Elizabeth C. Reade. 2001. Mass fumigation at the university library in Suva. International Preservation News 24: 5-6.

Forstmeyer, Kerstin. 2001. The restoration of the estate register of the chapter at Ellwangen: A case study on the subject of minimal intervention. The New Bookbinder 21: 72-77.

Fry, Thomas K. 2000. Library remote storage in Colorado. Colorado Libraries 26, no. 1: 27-29.

Gehret, Carol L. 1999. Preservation from a collection development perspective. Acquisitions Librarian 21: 115-24.

Gertz, Janet. 2000. Selection for preservation in the digital age: An overview. Library Resources and Technical Services 44, no. 2: 97-104.

Haberditzl, Anna. 2001. From bookbinding, via restoration, to preservation: The Institute for Preservation of Archival and Library Material in Ludwigsburg. The New Bookbinder 21: 69-71.

Hall, Wendy. 2000. Oral history fast forward: From audiocassette to digital archive. Colorado Libraries 26, no. 4: 9-10.

Harris, Kenneth E. 2000. Saving the written word: Mass deacidification at the Library of Congress. Washington, D.C.: Library of Congress.

Henderson, Gwendolyn E. 2000. Preservation in a public library. Colorado Libraries 26, no. 1: 39-40.

Herring, Mark Y. 2000. Archival treasure: Blessing-or burden in disguise? American Libraries 31, no. 7: 41-43.

Hingley, Mark. 2001. Success in the treatment of parchment and vellum using a suction table. Journal of the Society of American Archivists 22, no. 1: 71-77.

Jarrell, Michael C. 1999. Providing access to three-dimensional collections. Reference and User Services Quarterly 38, no. 1: $29-32$.

Johnson, Kathleen A., and Katherine L. Walter. 2000. Preservation microfilming project: The Mari Sandoz Collection at the University Libraries, University of Nebraska-Lincoln. Nebraska Library Association Quarterly 31, no. 4: 37-39.

Johnson, Steve. 1999. Library disaster recovery: The fine art of gift raising. Library Collections, Acquisitions, and Technical Services 23, no. 1: 133-34.

Johnston, Sharon. 1999. An African American album: Preserving local history on CD-ROM. American Libraries 30, no. 3: 54-56.

Jordan, Sophia K. 2000. A review of the preservation literature, 1993-1998: The coming of age. Library Resources and Technical Services 44, no. 1: 4-21.

Kamel, Pauline. 1999. Conservation treatment of rare books. Feliciter 45, no. 2: 108-12.

Kane, Kim. 2001. You too can do a disaster plan. Library Mosaics 12, no. 2: 12-13. 
Kellerman, L. Suzanne. 1999. Combating whole-book deterioration: The rebinding and mass deacidification program at the Penn State University Libraries. Library Resources and Technical Services 43, no. 3: 170-77.

Kenney, Brian J. 2001. Central libraries in uncertain times. Library Journal 126, no. 19: 36-37.

Kisling, Vernon N., Stephanie C. Haas, and Pamela S. Cenzer. 2000. Last copy depository: Cooperative collection management centers in the electronic age. Collection Management 24, no. 1/2: 87-92.

Lane, James, and Joy Gudz. 2000. Reformatting operations at the New York Public Library. Microform and Imaging Review 29, no. 2: 46-49.

Larsen, Paul S. 1999. Books and bytes: Preserving documents for posterity. Journal of the American Society for Information Science 50, no. 11: 1020-27.

Law, Cliff. 2001. PANDORA: The Australian electronic heritage in a box. International Preservation News 26: 13-17.

Lossau, Norbert, and Martin Liebetruth. 2000. Preservation issues in digital imaging technology. Microform and Imaging Review 29, no. 4: 122-30.

Lunde, Diane B. 1999. When disaster strikes: A case studyColorado State Libraries, July 28, 1997. The Serials Librarian 36, no. 3/4: 363-82.

MacKenzie, George P. 2000. Working for the protection of the world's cultural heritage: The International Committee of the Blue Shield. Journal of the Society of American Archivists 21, no. 1: 5-10.

Mader, Sylvia. 2001. Catastrophes and catastrophe management. International Preservation News 25: 12.

Marshall, Vanessa. 1999. The National Preservation Office: Raising preservation awareness in the UK now: Planning for the future of our past. Alexandria 11, no. 3: 191-201.

McGlamery, Patrick. 2000. The impermanence of maps in the information age. Inspel 34, no. 1: 52-59.

Merrill-Oldham, Jan, and Jutta Reed-Scott. 1999. ARL SPEC Kit \#242, Library storage facilities, management, and services. Washington, DC: Association of Research Libraries.

Moore, Mary. 1999. Attack of the killer mold spores. American Libraries 30, no. 3: 46-49.

Muir, Adrienne. 2001. Legal deposit and preservation of digital publications: A review of research and development activity. Journal of Documentation 57, no. 5: 652-82.

National Information Standards Organization. 2001a. ANSI/NISO Z39.79-2001 Environmental conditions for exhibiting library and archival materials. Bethesda, Md.: NISO Pr.

. 2001b. ANSI/NISO Z39.62-2000 Eye-legible information on microfilm leaders and trailers and on containers of processed microfilm on open reels. Bethesda, Md.: NISO Pr.

. 2000a. ANSI/NISO Z39.77-2001 Guidelines for information about preservation products. Bethesda, Md.: NISO Pr. . 2000b. ANSI/NISO/LBI Z39.78-2000 Library binding. Bethesda, Md.: NISO Pr.
Nichols, Stephen G., and Abby Smith. 2001. The evidence in hand: Report of the Task Force on the Artifact in Library Collections. Washington, D.C.: Council on Library and Information Resources.

Page, Julie A. 1999. When disaster strikes: First steps in disaster preparedness. Serials Librarian 36, no. 3/4: 347-61.

Palma, Maria Antonieta. 2001. Preservation training: Chile is now in Brazil's footsteps. International Preservation News 25: 19-20.

Parkes, Mitchell. 1999. A review of the preservation issues associated with digital documents. Australian Library Journal 48, no. 4: 358-77.

Pearson, Colin, and Steve King. 2000. Passive environmental control for small cultural institutions in Australia. Australian Academic and Research Libraries 31, no. 2: 69-78.

Perushek, Diane, and Kathlin Smith. 1999. Preserving Chinese historical resources: Report on an international cooperative microfilming project. Asian Libraries 8, no. 1: 279-86.

Plebani, Lydia. 1999. Clean method to fight pest invasion. International Preservation News 20: 16-17.

Poole, Francis C. 1999. Basic strategies for film preservation in libraries. Technical Services Quarterly 16, no. 4: 1-10.

Porck, Henk J., and René Teygeler. 2000. Preservation science survey: An overview of recent developments in research on the conservation of selected analog library and archival materials. Washington, D.C.: Council on Library and Information Resources.

Preiss, Lydia. 1999. Learning from disasters: A decade of experience at the National Library of Australia. International Preservation News 20: 19-26.

Read, John. 1999. Parish map preservation project and the use of digital holography, CDs, and computers to copy, view (and preserve) old maps. LASIE 30, no. 3: 45-53.

Rebsamen, Werner. 2002a. Editions bindings vs. library bindings. The New Library Scene 20, no. 3: 1-4.

- 2002b. "Mouse trap" bindings. The New Library Scene 21, no. 2: 1-4.

. 2002c. Edition bindings vs. library bindings. The New Library Scene 20, no. 3: 1-4.

2002d. Hand bookbinders: A lost art? The New Library Scene 20, no. 2: 1-2.

Reinerston-Sand, Mary. 1999. What I learned from the flood of 1997 or, why archival class is essential. American Libraries 30, no. 3: 40-41, 43-45.

Rothenberg, Jeff. 1999. Avoiding the technological quicksand: Finding a viable technical foundation for digital preservation. Washington, D.C.: Council on Library and Information Resources.

Schaffner, Bradley L., and Brian J. Baird. 1999. Into the dustbin of history? The evaluation and preservation of Slavic materials. College and Research Libraries 60, no. 2: 144-51.

Schobernd, Elizabeth M. 1999. Preservation: Everybody's job. Illinois Libraries 81, no. 1: 5-10. 
Slate, John H. 2001. Not fade away: Understanding the definition, preservation, and conservation issues of visual ephemera. Collection Management 25, no. 4: 51-60.

Smith, Abby. 1999a. Preservation in the digital age: What is to be done? American Libraries 30, no. 3: 36-39.

1999b. Why digitize? Washington, D.C.: Council on Library and Information Resources.

- 1999c. The future of the past: Preservation in American research libraries. Washington, D.C.: Council on Library and Information Resources.

Smith, Catherine. 2000. The preservation of printed music collections in libraries: A review of the literature. Australian Library Journal 49, no. 2: 119-38.

Smith, Elizabeth H. 1999. Mold abatement in a remote storage facility. Library and Archival Security 15, no. 1: 75-82.

Smith, Margit J. 2001. Paper splitting as a preservation option. Archival Products News 8, no. 1: 1-3.

Stoker, David. 1999. Should newspaper preservation be a lottery? Journal of Librarianship and Information Science 31, no. 3: 131-34.

Strauss, Robert J. 2000. Mass-deacidification: Where it fits in with reformatting. Microform and Imaging Review 29, no. 1: 8-10.

Tait, Jennifer, and Philippa Sterlini. 1999. Care and conservation of architectural plans: A survey of current practice in the UK and Ireland. Journal of the Society of Archivists 20, no. 2: $149-59$.

Temby, Mary A. 2001. Mould: The invasive intruder! Australian Library Journal 50, no. 2: 175-80.

Tennant, Roy. 1999. Time is not on our side: The challenge of preserving digital materials. Library Journal 124, no. 5: $30-31$.

Teper, Thomas H. 2001. A collection assessment of University of Kentucky's newspaper negatives. Microforms and Imaging Review 30, no. 4: 113-126.

Walls, David. 2000. A means to a different end: A survey of the Negative Microfilm Collection at Yale. Microform and Imaging Review 29, no. 3: 73-78.

Wheatley, Paul. 2001. Migration: A CAMiLEON discussion paper. Ariadne 29: 1-13.

Wiseman, Christine, and Sharla Darby. 2001. Preservation workshop evaluation. Library Resources and Technical Services 45, no. 2: 95-103.

Wishard, Lisa A., and Linda R. Musser. 1999. Preservation strategies for geoscience literature: New technologies for an old literature. Library Resources and Technical Services 43, no. 3: 131-39.

Zachary, Shannon. 2000. Library pamphlet binding. Archival Products News 8, no. 1: 4-8. 